\title{
Lo Estético Heterónomo
}

\author{
Por NeLLy Festini IlLich
}

La investigación filosófica sobre Estética en la época contemporánea, dedica preferente atención al análisis teórico de lo estético autónomo, procurando ubicarlo dentro de la experiencia humana para fijar su esencia y significado. Considera además, que la desorientación en esta materia se debe a las múltiples perspectivas heterónomas adoptadas, las que no sólo han originado el falseamiento del fenómeno estético, sino el uso de metodologías inconvenientes y el estudio excesivo de problemas secundarios como si fueran fundamentales.

A través del examen crítico han perdido su autenticidad añejos prejuicios que en determinados casos se persiguen mantener hasta la actualidad, los cuales no pueden dejar sino aportes a favor de ciertos problemas pertenecientes a disciplinas auxiliares de la Estética, pero que no tratan el tema céntrico de la misma a la luz de un plenteamiento propio liberado de sugestiones y aseveraciones extraestéticas. Cabe pues, fortalecer esta actitud legítima que aparece dispersa en varias investigaciones filosófico-estéticas contemporáneas y exponerla en conjunto, lo más completa posible, en cuanto al señalamienta de los asuntos que supone y añadir a ellas algunas reflexiones personales que podrían asegurar la unidad y.solidez' de lo estético autónomo. Los seis puntos de vista que a continuación se describen e interpretan se agruparán en tres, teniendo en cuenta la afinldad de sus argumentos; todos resumen la inquietud filosófica desarrollada en el ahondamiento de la 
interrogante ¿qué es lo estético? de cuya solución depende el sentido de la vivencia humana más inefable y creadora. (")

El hedonismo estético en sus formas de sensualismo extremo 0 moderado, apoya sus postulados en manifestaciones de índole biológica que responden a específicas alteraciones de los sistemas nervioso o circulatorio, o se refieren a procesos de origen sexual y a excitaciones de los sentidos. Lo estético se engendra y ambienta bajo los cánones mencionados, siendo el placer con base orgánica, sexual o sensorial, la personificación de la belleza. No importa la calidad del estímulo, lo que interesa es la consecuencia de placer o de displacer, la jerarquía estética se forja por el grado de intensidard de la impresión. Creador y contemplador deben experimentar una compensación biológica en la reacción hedónica, pues, la ilusión expresiva prende únicamente, en virtud de tales justificativos.

G. Hirt, Th. Ziehen, Konrad Lange y K. Gross, por citar a los más representativos, sostienen. estas consideraciones y no admiten otro recurso ideológico que pueda sustituirlas. Sinembargo, una madura revisión de dichos principios los aclara y al mismo tiempo los supera. ¿Se produce cacaso estimativa estética siempre que se vivencia goce sensual? y en forma inversa ¿no advierte el sujeto goce sensorial en circunstancias que son opacas y ciegas al mundo estético?. Por lo demás, la calidad del estímulo determina, sin lugar a duda, la presencia de la belleza y de las otras estructuras afines, cosa que no sucede biológicamente. La heteronomía del pensamiento estético biologista es evidente, pero innegable su aporte para la Psicología del Arte.

De mayor alcance son las apreciaciones de carácter psicologista, se pone el acento en estados afectivos, en sentimientos pe-

(*) La presente enumeración de las orientaciones heterónomas no incluye las direcciones gnoseológico-estética y metafísica, porque sus principios son indirectamente revisados en las seis modalidades que constituyen el tema primordial de estas reflexiones y en los conceptos finales que sintetizan el sentido de lo estético puro. 
culiares que arrastran variados procesos imaginativos creadores sustentados por un goce típico. Los atributos estéticos convertidos en sentimientos se trasladan al objeto que impresiona, transformándolo y cubriéndolo de una aureola de especial atracción o rechazo emocional. El sujeto las mira "como si" estuvieran enfrente y al mismo tiempo, "como si" contemplara gozoso su propia subjetividad capaz de producir el objeto que advierte. No existe vida estética desligada de la experiencia concreta, toda inferencia o deducción para organizarla son inadmisibles.

Los defensores del emocionalismo, de la Estética como Psicología aplicada, del experimentalismo estético y de la Proyección Sentimental, son criticados por la tendencia filosófica quien exhibe sus contornos negativos e indica sus contribuciones. Lo estético se ofrece en una clase de vivencia y no por ello es en esencia un modo vivencial, los sentimientos estéticos abren a la vida anímica el "ontos" de lo trágico, cómico, sublime, bello, etc., sin identificarse unos con otros. Más aún, el goce viene a ser un resultado, un eco expresivo humano que apunta, como atraído por imán, hacia la objetividad que lo inspira, sus variantes corresponden, para poderse diferenciar, a grados de interés o valiosidad recurriendo entonces a determinado perfil que no es el goce mismo.

Desde las teorías de Th. Lipps (1), hasta las de E. Meumann (2), De W. H. Parker (3), Fr. Kainz (4), M. Geiger (5), etc., se mantiene en líneas generales a tónica psicológica, formidable es verdad por el análisis del sentimiento estético, deola vivencia de creación y contemplación y de la imaginación creadora; empero, limitada en su afán heterónomo de hacer lo estético "substancia psíquica".

La influencia de la colectividad sobre la vida de cada hombre es vigorosa y definitiva, permite que surjan inquietudes sociales superiores, a las cuales el individuo independientemente, no puede

(1) Th. Lipps - "Fundamentos de la Estética".

(2) E. Meumann - "Sistema de Estética".

(3) De W. H. Parker - "The Principles of Aesthetics".

(4) Fr. Kainz - "Estética".

(5) M. Geiger - "Estética". 
llegar. La corriente socio-estética basándose en dicha finalidad, cree que los sentimientos de colaboración, solidaridad, armonía social y su respectiva satisfacción, son la única belleza que puede crear el ser humano. De ahí que los objetos tienen que proyectarse a las conciencias mediante nexos de simpatía y por la humanización del objeto cuando éste no expresa vida colectiva. El Arte cuya meta debe ser la social, sirve de medio adecuado para suscitar experiencias estéticas, estando el genio artístico predeterminado a traducir en su obra las alternativas de la sociedad en forma de añoranza, anhelo o realidad. Tanto la teoría social del Arte, cuanto el sociologismo propiamente dicho, aceptan con pequeñas diferencias que el hecho estético es un sentimiento social peculiar y no observan al igual que en la posición psíquica, la huella "óntica" que ese sentimiento lleva consigo y de cuya naturaleza depende. J. M. Guyau, H. Tayne y otros, son la fuente de las especulaciones sociológicas actuales sobre el sentido del Arte elaboradas por eminentes estudiosos contemporáneos, quienes han planteado, asimismo, la polémica irreconciliable entre sociologistas y esteticistas del Arte.

La relación existente entre los fenómenos sociales y los estéticos no conducen a la asimilación del uno por el otro. Al establecer el deslinde de sus campos, la efectividad puesta en juego para producir solidaridad armonía y colaboración no es de índole estética, cunque a veces brote al mismo tiempo. El Arte en su contenido espiritual cextraestéticon considera/ lasposibilidad social, pero ésta no tiene carácter expresivo para la sensibilidad emocional si no ostenta a su vez, perfil estético, que le otorga un matiz especial más allá de los acontecimientos incluídos en el tema artístico y que la hace valer con singular perdurabilidad.

Lo comentado no excluye la correlación entre los sentimientos estéticos y los sociales; los primeros por ejemplo, promueven un afán de validez para los demás en lo que siente un sujeto y revelan un impulso lúdico que los vitaliza. La Sociología y Psicología del Arte reciben de los ensayos esbozados benéficos conocimientos que de ningún modo son las verdades primordiales de la Estética autónoma.

La fuerza de los acontecimientos y su conexión con estructuras materiales $y$ espirituales que progresan 0 retroceden en el devenir 
temporal, motivan investigaciones cuyo objeto básico es la historicidad, erigida en matriz de todas las manifestaciones humanas durante las distintas épocás. Dentro de esta orientación, los historiadores también pretenden definir lo estético reduciéndolo a la unidad que alcanzan los contenidos históricos en determinada época. Unidad que se hace explícita y sobre todo nítida, por la participación fecunda.del genio quien al crear su obra artística traduce su propia unidad histórica, vale decir sus experiencias diarias al contacto con el medio. Predomina tanto el fondo histórico en el Arte, que hasta la técnica y el material físico de trabajo exhiben historicidad, se amoldan a los ideales que imperan y son seleccionados por el genio en. virtud de este criterio. Vivir el mensaje artístico es penetrar certera y sutilmente en el mensaje de la vida, mejor aún que cualquier ciencia. En W. Dilthey (6) se afirma gran parte de estas apreciaciones, y así lo estético de inobjetable cuño histórico, queda ligado exclusivamente al Arte, la poesía y la Literatura.

No obstante la riqueza de los conocimientos delineados, muy provechosa para la Filosofía del Arte y la Historia del Arte y de la Estética, el destino unilateral y miope de la heteronomía estética se pone nuevamente de manifiesto. Es preciso no confundir el tema del ejemplar artístico con la expresividad de gracia; comicidad, belleza, etc., que transparenta; al primero, la historia lo domina y nutre, las segundas, sibien hunden sus raíces en el discurrir temporal, emergen cemougeśto expresivo valioso cuya fisonomía depende de aspectos especiales, que exigen estimativa apropiada fortalecida por un ímpetu de perennidad. Por lo tanto no es suficiente percibir historicidad, para admitir clima estético, ni tampoco rechazarlo en las cosas de la naturaleza exentas de simbolismo histórico.

El vehemente aliento espiritual hacia la perfección humana, viene a ser coordenada común a la bondad y belleza y uno de los fundamentos del moralismo estético. Algo más, lo bueno rige a lo bello cuya misión es producir cualidades éticas, ayudando al ejercicio de actos nobles, abnegados, etc., mediante la sublimación de

(6) W. Dilthey - "Vida y Poesía". 
tendencias egoístas. El cariz estético del objeto artístico conmueve en razón directa de su prestancia ética, hay un sino de formación interior en el Arte, si éste se desvanece, la producción creadora se trunca.

Con la visión fenomenológica de la experiencia ética y de la estética se rebasa la ingenua y empírica asimilación de ambas estructuras, correspondiéndoles en vía comparativa las condiciones que siguen: 19 la aprehensión del valor ético va unida a una imperiosa obligatoriedad de realizarlo y compromete la existencia humana, en cambio, la aprehensión de los valores estéticos no compromete la existencia misma de la persona ya sea aceptado o rechazado el valor. $2^{\circ}$ Los valores éticos asoman en las acciones y los estéticos pueden aparecer en los objetos y en las acciones. $3^{\circ}$ El soporte objetivo del valor ético se da como algo real, por el contrario, el soporte objetivo del valor estético a menudo muestra idealidad, ficción. $4^{\circ}$ Los valores éticos indican el sentido de una acción, no así los valores estéticos que revelan el significado de la expresión con que se manifiestan las acciones.

La revolución causada por las diferencias anotadas, trajo provechosas adquisiciones concernientes a la Teoría Literaria y Artística y a la Crítica, a quienes sirvió el derrotero trazado filosóficamente: lo estético es autónomo de lo ético; en un ejemplar artístico pueden ofrecerse elementos éticos y estéticos sin que ello conduzca a su identificación; los fenómenos estéticos a veces ocasionan fenómenośáticos y ca la inversa.verso»

La perfección humana llevada a un extremo de idealización que rebasa lo humano propiamente dicho, erige a Dios único poder capaz de suscitar sentimientos que proclaman el destino terreno y ultraterreno de individuos y colectividades. Esos sentimientos por su secreto encanto, observan los místicos de la Estética, son los genuinos fenómenos estéticos. He aquí otra posición heterónoma muy aguda, generalizada y persistente que admite convicciones referentes a la vida estética basándose en estos puntos: sentir la belleza por ejemplo es comprender la hermandad existente entre los hombres frente a lo divino; es proclamar en éxtasis, con mayor - menor intensidad, las creencias religiosas; es en último término, darle materialidad plástica al impulso primario de todo hombre en su constante conocimiento general del Universo. 
Rudolf Otto (7) empieza con el análisis fenoménica de lo Santo la singularización del hecho religioso, muy útil para notar su divergencia y correlación con los hechos estéticos. La vivencia religiosa lleva consigo un elemento irracional: lo Santo, imposible de confundirse con aspectos éticos o estéticos. Los rasgos típicos que lo Santo patentiza son: la presencia de algo remoto y superior a lo humano; insólito poderío y majestad ante el cual el hombre se siente siervo; avasallador dinamismo capaz de crear cosas, hechos y personas; misterioso y tremendo y a pesar de ello, atractivo, subyugante y merecedor de fe absoluta. La experiencia estética en general es heterogénea a lo Santo, solamente la sublimidad presenta algunos rasgos comunes que no son los esenciales. Es necesario reconocer además, la interdependencia de lo religioso y estético, al igual que sucedió con el aspecto ético, subrayando siempre la autonomía de cada uno. El Arte religioso cobra de este modo, interés especial que la Crítica recoge para el mejor conocimiento filosófico y artístico.

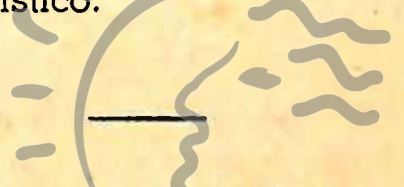

Admirable tarea crítica cumple la Estética Filosófica Contemporánea (") en afanosa búsqueda por la autonomía y la unidad. Destruye limitaciones, pautas equivocadas, indaga por un objeto claramente asequible yodiferenciado, dúctil a la investigación con la ayuda de uno o varios métodos homogéneos, en fin, detalla problemas y logra que "los esfuerzos teóricos desplegados no entorpezcan o desnaturalicen el propio fenómeno estético, por el contrario, confirma su contextura emocional y su íntima vinculación con la vida del ser humano y con los dominios de la cultura.

Lo estético autónomo es una estructura expresiva, figurativa valiosa con significado para la sensibilidad emocional creadora, se hace presente en cualquier objeto y es imprescindible on el Arte. Sus cualidades específicas: afectividad, transparencia, fragili-

(7) R. Otto - "Lo Santo".

(*) Muy importante son los estudios que las corrientes francesa, italiana y alemana, entre los que se puede mencionar los aportes dejados por: B. Croce - "Estética", E. Souriau - "L'Avenir de L'Esthétique", R. Bayer - "Essais sur la méthode en Esthétique" y N. Hartmann "Asthetik". 
dad, integralidad (naturaleza subjetivo-objetiva) y simbolismo, que aquí no es el caso revisar ( 8 ), no tienen equivalente vistas en conjunto, a los objetos preconizados por las concepciones heterónomas.

La Estética Filosófica Contemporánea abre un futuro promisor, pues, ha comenzado una labor enfocada con acierto y acreditada por abundante documentación. Ha intuido y recuperado la verdad de un objeto, cuya suerte parecía ser la variabilidad más caótica y el subjetivismo más arbitrarlo, que alimentaron huecas polémlcas en terreno extraño, lucubraciones estériles y forzadas.

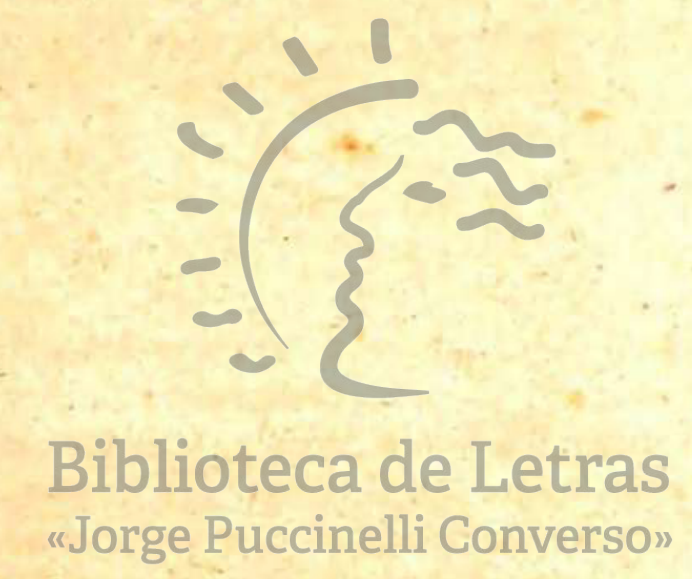

(8) N. F. I. : "Acerca de lo Estético". 